\title{
Developing Pacific leaders within a tertiary education setting through appreciative inquiry: A personal perspective
}

\section{ChERIE ChU}

\section{Abstract}

Against a background of national policy concern with enhancing the educational success of Pacific students, this paper offers a personal perspective on the potential of appreciative inquiry (AI) as an approach to leadership mentoring in tertiary education settings. It discusses how the four phases of AI were implemented in the author's mentoring activities and argues that AI is highly beneficial both for group and individual mentoring contexts. The paper concludes that mentoring relationships using AI, in which the mentor focuses on the protégé's strengths, has considerable value in growing leadership potential for Pacific people.

Tn its tertiary education strategy for 2007-2012, the Tertiary Education Commission (2007) noted that there is a need "...to significantly increase the success of young Pasifika peoples in the tertiary education system as currently the completion rates of Pasifika are lower than for any other group" (p. 32). Likewise, New Zealand's Ministry of Education Pasifika Education Plan (2009-2012) is focused on increasing retention and completion rates for Pacific students in tertiary education. A number of New Zealand tertiary institutions emphasise leader qualities in young Pacific students and offer programmes that build leadership skills. Many schools also encourage Pacific students to become leaders and enrol in university courses. 'Future Leaders of Tomorrow' is a motivational slogan developed to inspire these young people as they consider career plans post-school.

Historically, the umbrella term 'Pacific' has been used by the New Zealand Government to define the ethnic composition of people migrating from the Pacific Islands to Aotearoa/New Zealand (Cook, 
Didham, \& Khawaja, 2001). Bedford and Didham (2001) state that the term Pacific has been commonly and widely utilised by many people and institutions including educators, policy makers, community workers, the media and so on. However, the use of the term has often attracted generalisations about a group of people who are diverse. For this paper, I have defined Pacific people as those who can trace their ancestry to, and/or are citizens of, any of the territories understood to be part of the Pacific (i.e., Melanesia, Micronesia and Polynesia).

The development of leadership for Pacific people studying in New Zealand universities is the focus for this paper. Several years ago, as a developing mentor, I engaged with the philosophy of appreciative inquiry (AI), and this paper is focused on the experiences of developing leaders at Victoria University of Wellington, using an appreciative mentoring model. As I learnt more about AI, it was clear to me that this would become my way of life and learning - it would connect and engage me with others via a mentoring relationship. AI gave me insights to the beauty of understanding and utilising individuals' strengths for leadership development.

As there have been considerable underachievement rates over the past 30 years, I have focused on developing Pacific students as leaders to ensure that they are successful in their university studies and lives. As an academic in the university I strive to build positive mentoring relationships with all of my students so that they will excel in their studies. Mentoring Pacific students with the AI philosophy provides a positive appreciation of their strengths and their identities. AI is enabling in eliciting the powerful stories of courage and motivation amongst the students. The intention of this paper is to show that mentoring relationships between academics and Pacific students must be developed well, with an appreciation of their strengths.

\section{Mentoring and leadership}

There is still no comprehensive understanding of what leadership is, and there is no consensus on what is good or effective leadership (Smith, Montagno, \& Kuzmenko, 2004). As leadership is contextual I have defined leadership as "an influence of mutually-enabling and ethical change" (Sanga \& Chu, 2009, p. 10).

Mentoring has been used in different contexts with very little evidence of consensus of definition (Ehrich \& Hansford, 1999). For instance, Stein (1981) found 27 different phrases defining the term 
mentor, and Jacobi (1991) stated that the absence of a widely accepted operational definition of mentoring was a concern. Furthermore, the numerous definitions, some of which conflict, also subsume several distinct kinds of interpersonal relationships. However, while the term mentoring has various applications and understandings, there is one common feature in the understandings of the concept. Regardless of the nature of the mentoring relationship, which is targeted, and the purpose of the mentoring, there is a universal agreement that the concept revolves around the notion of 'supporting to grow.'

When close mentoring relationships develop between two or more people, there is ample opportunity for the growth of leadership. Many believe that if leadership is to be assumed, it can be enhanced by a mentoring relationship. For example, Sanga and Walker (2005) identify the importance of the role of a leader and note that "Leaders must be leaders of other leaders" (p. 90) and create opportunities for others to exercise leadership. Leaders need to take on the role of guardians of leadership ensuring that good leadership is evident through display of action and attitude. It is the role of leaders to take the initiative to act; they help others to see solutions and identify approaches to meet the challenges. In other words, leaders facilitate a shared leadership vision for the future. Leader developers, through a mentoring relationship, can achieve much of this.

\section{Appreciative inquiry}

Appreciative inquiry, a macro-organisational approach to organisational development, was developed by David Cooperrider and his colleague Suresh Srivastva of Case Western University in 1987 (Yballe \& O'Connor, 2000). AI focuses on the generative potential of positive images called anticipatory realities (Cooperrider, 1990). Cooperrider argues that positive images have the ability to organise and move human behaviour toward the realisation of the ideal (Yballe \& O'Connor, 2000). AI has been applied to public, private, and nonprofit organisations across the world and it emphasises exploring what works well. The sizes of groups in the organisations range from small work teams to multi-national corporations (Finegold, Holland, \& Lingham, 2002). The source of the positive image is drawn from people's experiences of 'the best of what is', and from an understanding of the life-giving forces, success factors, people, processes, and arrangements that help to achieve the best. These 
experiences are essential to providing the common dream which constitutes the positive image of what can be - the vision (Cooperrider, 1990).

Traditional modes of inquiry are based on the action research model of problem solving through a progression of steps: identifying the problems in the system, analysing the causes, and developing solutions and an action plan to solve the problem (French \& Bell, 1984). Finegold et al. (2002) believe that traditional problem solving has benefited the fields of physical sciences and technology, but not human systems issues. However, AI works on the premise that the knowledge required for solutions is contained in the relationships between people who construct reality through social interactions and conversations; that is, there are multiple ways of knowing realities and no one way is superior to any another. Stories, metaphors, meanings, and theories in the language become an important part of the process (Finegold et al., 2002). Fry and Barrett (2002) assert that when communities and organisations share their stories of success there appears to be a collective willingness to build from the lessons embedded in the stories. The authors place emphasis on the role of storytelling; via stories societies and families communicate what is good and worth holding on to. These moral themes create a sense of identity. Fry and Barrett describe appreciative stories as "magical constructions" (p. 267) that encourage reflection on meanings of friendship, wisdom, courage, justice, and innovation. Furthermore, these stories have the potential to move people beyond reflection to action.

AI is a revisioning model (Cooperrider \& Srivastva, 1987) and, as such, has the capacity to challenge the guiding assumptions of the culture of the organisation, to examine the positive aspects of the organisation, and to assist with development of new alternatives for social actions (Cooperrider, 2000). It points to one basic assumption: an organisation is a mystery to be embraced (Hammond \& Royal, 1998). According to Van Buskirk (2002), AI produces many positive effects through providing an interpretive ground that leads to a rethinking of practice and policies within an organisation's social construction. Instead of focusing on deficits or the problems of a group or organisation (French \& Bell, 1984), the AI inquiry process of asking questions to identify new potentialities and possibilities facilitates a focus on appreciating the best in people, and their world. 
Hammond and Royal (1998) adapted a model of AI that was originally conceived by Cooperrider and Srivastva (1987) which clearly displays the main differences between AI and paradigms of problem solving (see Figure 1). Hammond and Royal were keen to move away from the deficit perspective of seeking out problems and solutions to a more strengths-based approach of appreciation.

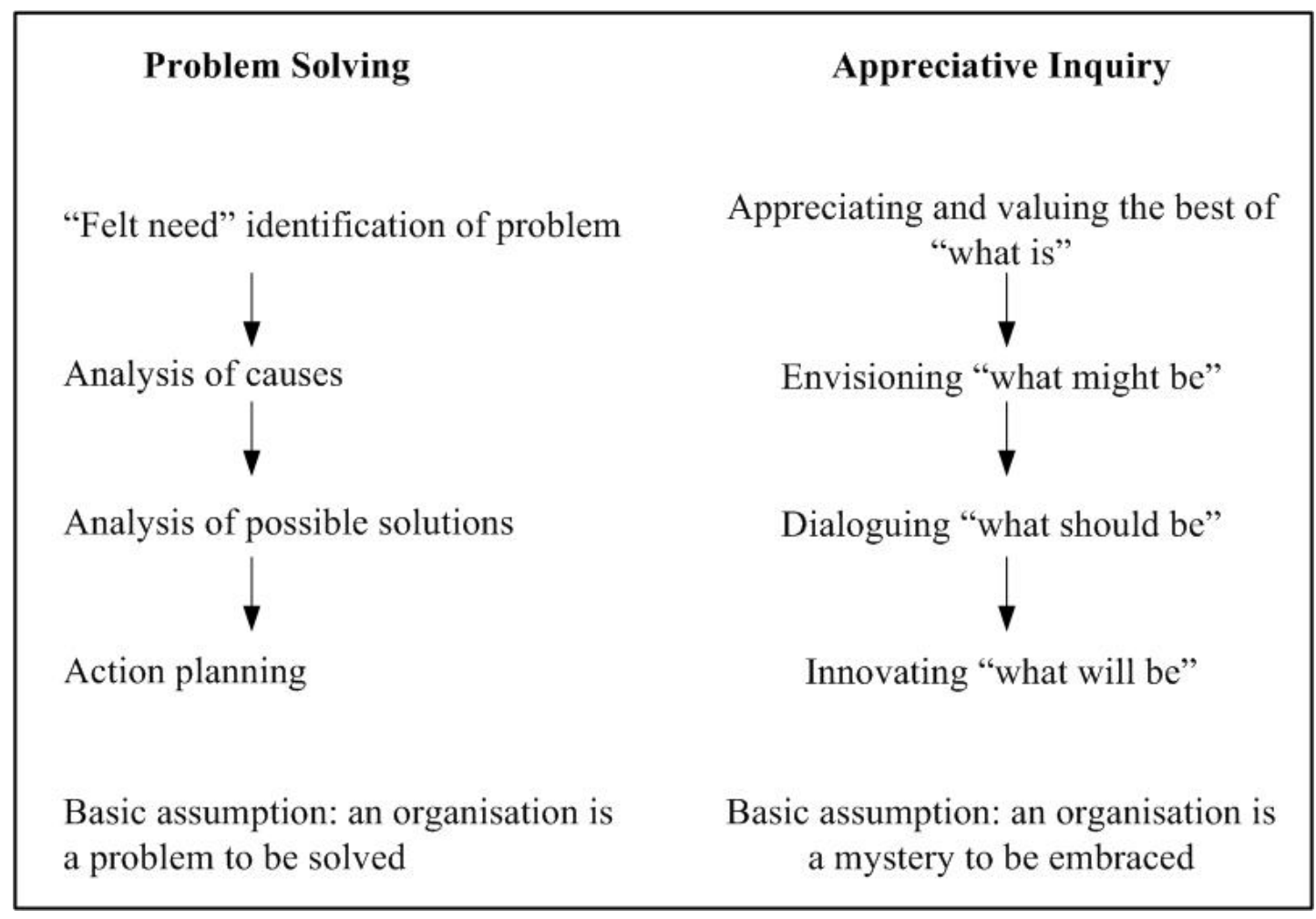

Figure 1: Differences between problem solving and AI

(Hammond \& Royal, 1998, p. 13)

\section{The four phases of appreciative inquiry}

Cooperrider's (1986) model of AI comprised four phases - discovery, dream, design and destiny - known as the 4-D process. These phases are defined below.

Discovery: consists of appreciating and discovering the best of "what is". During this phase, the primary task is to promote learning by sharing stories about the best times, and analysing the forces and factors that made them possible. Carefully crafted appreciative questions are used to elicit the stories, and essentially stories that give energy and vitality to the system become the focus. AI does not dismiss problems altogether but it offers a broader lens through which 
people can appreciate their system or context. People can interview one another to explore strengths, assets, positive experiences, and successes so that they can understand what made their moments of excellence possible.

Dream: members can envision what is possible and build upon strengths by having conversations grounded in knowledge created in the discovery phase. The dreams have been cued by asking positive questions and developing a picture of what the organisation could and should become according to people's deepest hopes and highest aspirations. Themes and patterns emerge that inspire hope and possibility. Underlying questions such as "What is the world calling us to become?" and "What might we become if our exceptional moments were the norm?" are part of this dream phase.

Design: during this phase, members devise short-term and longterm strategies to redesign the social, political, economic, and physical aspects of the group through dialogue. The task is to redesign the organisation's social architecture - norms, values, structures, strategies, systems, patterns of relationship, and ways of doing things that can bring dreams to life. By this process, commitment is built through dialoguing, debating, and creating; ultimately, everyone reaches a point of wanting to develop the shared vision of the organisation or community. For this to occur, it is important to have an inclusive context for conversation and an environment for creating possibilities together. Provocative propositions are used to stretch the system from where it is to where it wants to be. The members design the principles they want to live by.

Destiny: Using the principles of AI the group works to accomplish stated goals and to be innovative in accomplishing these goals. The destiny phase allows for 'what could be'. Through innovative ways, people can move the organisation closer to the ideals. Because the ideals are grounded in reality, people will have the confidence to try to make things happen. New networks and relationships can begin to affect the direction and meanings of the actions (Ludema, Whitney, Mohr, \& Griffin, 2003).

\section{Applications of appreciative inquiry}

The above description provides the fundamental process of AI used in contexts of organisational change. A number of recent studies illustrate the application of the AI process in educational settings and 
these studies demonstrate how AI can be utilised by educators to enhance people's lives. Mellish (1998) applied AI in a university setting, working with a Planning Dean charged with developing four existing departments into one new faculty. A collective view of the future was developed from the multiple perspectives of the people involved in the change process because the clients wanted to be reassured that the process was leading somewhere. At the beginning, quality time was needed for story-telling, which enabled commitment to the deliverables at the end of the process. In this process the role of the facilitator was important for it was necessary to have perceptive and anticipatory knowledge of the contextual factors of the group, engage in acute listening with an appreciative ear, demonstrate positive care of the group to achieve the best outcomes, and an insatiable curiosity about the day-to-day life of the university.

In another study, Yballe and O'Connor (2000) adapted the use of AI to develop appreciative pedagogy (AP) for constructing positive models for learning. AP, as a pedagogical adaptation of AI, takes on AI's basic values and social inquiry process. In the classroom environment, AP translates to a basis for experiences of students' success, valuing success as the building block of positive vision, belief in the profound connection between positive vision and positive action, and valuing social (face-to-face) inquiry. The use of an appreciative stance is beneficial to guiding the professors' everyday teaching. Appreciative pedagogy was useful to guide students to develop their competencies because of the tighter connection with personal experience. However, Yballe and O'Connor (2000) assert that AP is not merely a copy of AI, as the classroom environment is considerably different from an organisation. For instance, they noted that the organisation is tied to an environment in short and long-term ways whereas the classroom is temporary. The authors explain that the AP process affects the learning culture of the classroom, and teachers' and students' efforts are short term and limited to the self and the group. Their studies/research in a tertiary setting showed the use of AP in the classroom led to energised interactions that enabled the students to be more comfortable in public speaking. The students expressed hopeful views of the future, and developed more skills and confidence in using AI as a creative alternative to problem solving, and also positive attitudes toward other students. Finally, the students 
developed positive attitudes toward the professor, seeing him as a resource, guide, and helper.

In a third study, AI was applied in two urban Catholic schools experiencing some difficulties and challenges resulting from societal changes. The parents, students, staff and communities were all engaged in the AI process (Van Buskirk, 2002). The areas of focus were appreciating discipline - since everyone had diverse views about it - and appreciating community for all had different roles in developing the school communities. Other areas of focus for the schools' study involved appreciating student-faculty relationships, student friendships, and the culture and diversity of each school. Because of the AI process, transformations occurred in the way individuals related to their experiences; it transformed how they related to the best experiences of others and it transformed how they related to the most cherished traditions of the school (Van Buskirk, 2002).

Based on the Pygmalion phenomenon, Bloom \& Martin (2002) argued that academic advisors need to treat each student as a future physician, lawyer, or other influential person. They identified how AI can be used to improve academic advising, suggesting that the mentor should:

1) believe in each student and treat them the way you would want your son/daughter/best friend to be treated

2) make use of open-ended questions to draw out what the students enjoy doing, their strengths, and their passions. Listen carefully to each answer before proceeding to ask the next positive question (Discovery phase)

3) encourage and help students to develop a vision of what they might become and then assist them in developing their career and life goals (Dream phase)

4) give students a clear idea of what they will need to do by devising goals that are real and achievable so that their dreams come true (Design phase)

5) be there for students when they stumble, believe in them every step of the way, and help them continue to update and refine their dreams as they progress (Destiny phase).

AI is fundamentally an inquiry into human systems. Its key strength is its adaptability in terms of both the range of contexts it can 
be applied to, and the modifications it can accommodate in these contexts. AI is a philosophy that requires appropriate application and has the power to facilitate collaborative relationships between people with the practitioners applying it in a way that best fits the context. The main point is that it requires a focused dialogue or conversation and an open sharing of learning. With regard to mentoring and AI, I found that there is a strong connection between the two concepts; both methods are connecting people through relationships and enhancement of knowledge. Furthermore, both mentoring and AI maximise performance of individuals and communities. Appreciative inquiry is paramount for Pacific student development, as it affirms the value of knowledge, of past and current experiences - we do not rely on another body of knowledge to inform us of our relationship potential. AI allows us to start with what we know.

\section{Appreciative mentoring relationships}

AI, while highly beneficial for group contexts, can also be applied to individuals. Within a tertiary setting Pacific students have many levels of responsibilities beyond the student role, and a range of issues and unique factors that impact on their lives. In one case, I explored with a student, Aliani, the possibilities for making her participation in an overseas trip to Hawaii a reality. At first I raised questions designed to elicit positive thinking. Examples of such questions were, "What are the challenges for you?"; "What are some things we could help with? and "How can we support you better?" In previous mentoring situations, I had found that Pacific students had made decisions hastily without thinking of possible strategies or options that might in fact enable them to reach their goals. As part of the mentoring discussion, we talked at length about Aliani's potential to grow by being involved in the experiences and opportunities that would come out of the Hawaii trip - activities such as organising fundraising activities, by making a presentation, and by engaging with the other students in the group. By meeting these challenges, which are not typically part of a tertiary student's experience at the university, it was anticipated that Aliani would potentially grow as an individual. Through active discussion, we found different ways of looking at her problem, resulting in finding solutions and possibilities for action. 
The above account highlights an important point. Mentoring involves motivating the protégé; the mentor is committed to helping protégés make positive changes. This commitment is demonstrated through spending time to talk in depth about the concerns, needs, and aspirations of the protégé, and mentors consistently showing belief in those whom they mentor (Sanga \& Walker, 2005). Furthermore, having high expectations allows protégés to rise to the expectations, as well giving them hope and trust. In this way, protégés feel good about themselves and aspire to reach the expectations. Another important point is that the mentor has to be accessible and in direct contact with the protégé but, as they gain confidence in themselves and in the relationship, they require less personal contact. Until they reach this point, however, the mentor must be frequently accessible giving advice and time freely to protégés. Aliani's story also indicates the importance of nurturing as an aspect of leadership development (Maxwell \& Dornan, 1997) - it was important to provide her with opportunities to succeed and grow. Indeed, mentoring gave her personal strength and helped her to remain secure amongst her peers. It was about supporting her to recognise that she had the potential to meet her challenges and reach a higher level of accomplishment. It was assumed of course, that she had the potential; as her mentor it was up to me to help her discover it.

\section{Leadership cluster}

Leaders must create opportunities for others to lead (Sanga \& Walker, 2005). In providing support to others to assume leadership, we considered it was important to provide nurturance to the community of leaders through setting up a cluster group. In a university cluster group, comprising students and academic mentors, we applied an AI framework to a leadership development process designed to enhance our personal and professional lives. While leadership was explored and discussed within an AI framework, it was not explained in specific terms. In these meetings, members were encouraged to share and discuss examples of high-quality leadership that they had experienced or observed and, consistent with the AI process of accentuating the positive, selecting such an example provided a positive approach to group discussions.

Following the sharing of positive experiences, members were also encouraged to share one specific issue or challenge they were facing 
in their leadership and to follow this up with a positive view on any of the challenges shared. In this way, the group was able to utilise its combined leadership knowledge and provide alternative perspectives, so that the person facing the challenge did not remain fixated on the unsolved problem. This process enabled members to think, to learn, to discuss, to develop insights, and to grow together as a group. It was facilitating more effective leadership.

In my role as an AI facilitator, I ensured that the group members were reminded of our purpose and to provide examples of issues encountered in their leadership roles. We continually sought positive stories and cases of leadership development that could be shared. Accordingly, through our discussion as a small group, we learnt to apply an appreciative perspective to ourselves. The stories and learning points provided specific enabling factors and principles for us as students of leadership to consider personally and for our communities. As a group, we aimed to maintain a positive attitude and refrain from applying a deficit perspective to any challenges raised, and by engaging in this manner we successfully identified learning points. This AI approach to the cluster group's discussions helped modify our personal attitudes; we were more positive about situations. Students noted how their perspectives had changed when approaching problems, with one student also observing that he was more aware of challenges at his workplace.

In this case, cluster group members had a range of previous experience of working together in various leadership and mentoring initiatives. Therefore, members brought to the cluster relationships prior experience and shared values of trust, respect, and honesty. This was significant for the success of this group because sometimes members disclosed personal and professional information that needed to be treated with respect and in confidence. It was deemed essential for the AI mentor to ensure that trust was developed from the outset.

Discussion topics for the cluster meetings were dependent on individuals' experiences and involvement in leadership activities with our ethnic and cultural backgrounds influencing our experiences and perspectives on leadership, and this provided meaningful and relevant learning. Since the AI process elicited positive and enabling factors, there were many stories of cultural leadership practices and when these were shared, individuals learnt key values, principles, and beliefs on leadership. A new Pacific knowledge on leadership 
developed and we were able to select what was relevant learning and apply it to leadership practice. This knowledge was focused on us as young leaders through using our own knowledge, our own stories of courage, of hope, of being part of a collective, and being the enablers of our own communities.

The cluster experience demonstrates that when the AI philosophy and approaches to mentoring are combined with leadership development, it can help to generate stronger relationships between people. Mentoring grows with the development of relationships. The focus is on enlarging individuals' perspective, listening carefully to the leadership needs, and then providing the opportunities to grow. This is the power of AI as a mentoring philosophy. In the cluster, people were connected and worked to support and encourage one another. With the help of an appreciative perspective, we created relationships of influence. Four years after the cluster was established with five students, it has grown to 100 members and this continuation and growth clearly indicate the desire of Pacific students for leadership development opportunities.

The establishment of a mentoring relationship does not necessarily ensure that an effective mentoring relationship will evolve. For this to happen, it is necessary for the mentor and mentee to know and understand each other well and to establish common goals/a shared vision. The main responsibility for this lies with the mentor. In my experience, taking the time to get to know the student - over coffee sessions for, instance - and using AI philosophy allows for conversations that reveal the protégé's concerns/interests/life (at a deeper level than would normally be the case - about family, church, friendships, student life, sports, interests, and hobbies. Generally, it is necessary to have such conversations outside lecture times, so it has been important to be visible around the university where the Pacific students congregated. Taking the time to mingle with students and give them time to think about issues is important.

It is evident that evaluating AI is work in progress. As a mentoring philosophy AI is highly dependent on the mentor's knowledge and crafting of the appreciative principles. As AI is discussed here, the approach is not easily transferable to another context. Further, there is the need for an evaluation of AI. Perhaps, an integrated use of AI and critical theory can help to deepen insight and recognition of the complexity in human endeavours. AI remains as a philosophy with 
little critique to evaluate the process. Therefore, while there is some commentary on its limitations, there is still a lot of AI territory to explore and discover. This paper is one attempt to add to the limited body of knowledge of AI.

\section{Concluding remarks}

Leadership development for Pacific students in tertiary institutions is an area yet to be fully explored, although some institutions offer suitable short to medium-term leader-focused initiatives. To develop students as leaders, support programmes and policies can build in mentoring for leadership strategies. A good mentoring relationship can offer positive change in individuals' lives. Some academics I encountered when I was a student myself became involved in my life and created a close relationship focused on learning through mentoring. This paper offers a starting point for discussion about mentoring and leadership using the AI philosophy.

As a philosophy, AI has considerable value. During my mentoring journey - first as a protégé and then a mentor - and as I have begun to understand AI more, I have realised how effective it is in developing mentoring relationships with Pacific students in tertiary education. AI is concerned with relationships, and mentoring is concerned with the development of relationships. To make mentoring worthwhile, a mentor must be able to draw out the strengths of an individual via a relationship. Mentoring is concerned with developing an individual's strengths within a nurturing relationship between mentor and protégé, and being a positive influence in a protégé's life. By focusing on the protégé's strengths, the mentor helps the protégé to believe in what they have rather than what they do not. AI makes this possible in an adaptable and credible way. By working with individuals to discover their potential and provide the encouragement and experience for selfdevelopment, AI offers countless possibilities.

\section{References}

Bedford, R., \& Didham, R. (2001). Who are the 'Pacific peoples'? Ethnic identification and the New Zealand census. In C. Macpherson, P. Spoonley, \& M. Anae (Eds.), Tangata O te Moana Nui: The evolving identities of Pacific peoples in Aotearoa/New Zealand (pp. 21-43). Palmerston North: Dunmore Press. 
Bloom, J., \& Martin, N. A. (2002). Incorporating appreciative inquiry into academic advising. The Mentor: An Academic Advising Journal, 4(3), Retrieved from http://www.psu.edu/dus/mentor/020829jb.htm

Cook, L., Didham, R., \& Khawaja, M. (2001). Who are the 'Pacific peoples'? Ethnic identification and the New Zealand census. In C. Macpherson, P. Spoonley, \& M. Anae (Eds.), Tangata $O$ te Moana Nui: The evolving identities of Pacific peoples in Aotearoa/New Zealand (pp. 44-65). Palmerston North: Dunmore Press.

Cooperrider, D. L. (1986). Appreciative inquiry: Toward a methodology for understanding and enhancing organizational innovation. Unpublished doctoral dissertation, Case Western Reserve University, Cleveland, Ohio.

Cooperrider, D. (1990). Positive image, positive action: The affirmative basis of organizing. In S. Srivastva \& D. L. Cooperrider (Eds.), Appreciative management and leadership: The power of positive thought and action in organizations (pp. 91-125). San Francisco, CA: Jossey-Bass.

Cooperrider, D. L. (2000). Positive image, positive action: The affirmative basis of organizing. In D. L. Cooperrider, P. F. Sorenson, Jr., D. Whitney, \& T. F. Yaeger (Eds.), Appreciative inquiry: Rethinking human organization toward a positive theory of change (pp. 123-129). Champaign, IL: Spite.

Cooperrider, D. L., \& Srivastva, S. (1987). Appreciative inquiry in organizational life. In R. Woodman \& W. Pasmore (Eds.), Research in organizational change and development (Volume 1, pp. 129-169). Greenwich, CT: JAI Press.

Ehrich, L. C., \& Hansford, B. C. (1999). Mentoring: Pros and cons for HRM, Asia Pacific. Journal of Human Resources, 37(3), 92-107.

Finegold, M. A., Holland, B. M., \& Lingham, T. (2002). Appreciative inquiry and public dialogue: An approach to community change. Public Organization Review: A Global Journal, 2, 235-252.

French, W. L., \& Bell, C. B. (1984). Organization development: Behavioral science interventions for organization improvement. Englewood Cliffs, NJ: Prentice-Hall.

Fry, R. E., \& Barrett, F. (2002). Rethinking what gives life to positive change. In R. E. Fry, F. Barrett, J. Seiling, \& D. Whitney (Eds.), Appreciative inquiry and organisational transformation: Reports from the field (pp. 263-278). Westport, CT: Quorum.

Hammond, S. A., \& Royal, C. (1998). Lessons from the field: Applying appreciative inquiry. Texas: Thin Book.

Jacobi, M. (1991). Mentoring and undergraduate academic success: A literature review. Review of Educational Research, 61(4), 505-532. 
Ludema, J. D., Whitney, D., Mohr, B. J., \& Griffin, T. J. (2003). The appreciative inquiry summit: A practitioner's guide for leading large-group change. San Francisco: Berrett-Koehler.

Maxwell, J. C., \& Dornan, J. (1997). Becoming a person of influence. Nashville, TN: Thomas Nelson.

Mellish, L. (1998). Strategic planning. In S. A. Hammond, \& C. Royal (Eds.), Lessons from the field: Applying appreciative inquiry (pp. 123-144). Texas: Thin Book.

Ministry of Education. (2009). Pasifika education plan 2009-2012. Wellington: Author.

Sanga, K. F., \& Chu, C. (2009). Living and leaving a legacy of hope: Stories by new generation Pacific leaders. Wellington: He Parekereke, Institute for Research and Development in Maori and Pacific Education, Victoria University of Wellington.

Sanga, K. F., \& Walker, K. D. (2005). Apem moa Solomon Islands leadership. Wellington: He Parekereke, Institute for Research and Development in Māori and Pacific Education, Victoria University of Wellington.

Smith, B. N., Montagno, R. V., \& Kuzmenko, T. N. (2004). Transformational servant leadership: Content and contextual comparisons. Journal of Leadership \& Organizational Studies, 10, 34-40.

Stein, S. L. (1981). Sex differences in expectations of mentors. Paper presented at the Annual Meeting of the American Educational Research Association, Los Angeles, CA.

Tertiary Education Commission. (2007). Tertiary education strategy 2007-2012. Wellington: Author.

Van Buskirk, W. (2002). Appreciating appreciative inquiry in the urban Catholic school. In R. E. Fry, F. Barrett, J. Seiling \& D. Whitney (Eds.), Appreciative inquiry and organizational transformation: Reports from the field (pp. 67-98). Westport: Quorum Books.

Yballe, L., \& O'Connor, D. (2000). Appreciative pedagogy: Constructing positive models for learning. Journal of Management Education, 24(4), 474483.

\section{The author}

Cherie Chu is a senior lecturer in Education at Victoria University of Wellington and a trainer-facilitator who has worked in the tertiary education sector for over 12 years. Her research is focused on the development of learners in universities and she is a published author of a number of papers in this field.

Email: cherie-chu@vuw.ac.nz 